physical properties which afford no evidence of being influenced by molecular complexity.

In the second are substances like the acids, water, and the alcohols, for which the disturbing factor is, no doubt, molecular complexity.

The question of the generality of the results obtained is next discussed. It is evident :

(I) That over such temperature ranges as the observations extend the results obtained at a particular value of the slope may be regarded as general for all liquids, with the exception of the alcohols, for which the relationships vary slightly as the slope alters. A general expression connecting the viscosity coefficient with the slope is given.

(2) It is further indicated, from comparisons made by the use of slopes which varied from liquid to liquid, and which were chosen according to definite systems, that in the present state of the question equal slope is the most suitable condition at which to compare the viscosities of different liquids.

With respect to the relationships existing between the magnitudes of the comparable temperatures of equal slope, it appears :-

(1) That these vary in a regular way with the chemical nature of the substances, except in the case of liquids like benzene and propylene dibromide, giving viscosity curves which are abnormal when compared with those of their homologues.

(2) The temperature relationships may also be regarded as general and thus independent of the value of the slope, except in the case of the alcohols, which, in this respect, as in that of viscosity at equal slope, are anomalous.

The rest of the memoir is concerned with the discussion of certain general conclusions regarding physicochemical comparisons ; and it finally deals with other possible methods of obtaining and comparing viscosity magnitudes.

\section{THE DYNAMICS OF THE ATMOSPHERE.}

UNDER this title a series of articles appeared in the Meteorologische Zeilschrift for May, August, and Septem ber, 1893, from the pen of Prof. M. Möller, of Brunswick, which treat of many of the important processes that are at work in our atmosphere.

The principal feature in these discussions is that the author treats the various phenomena as the result of complicated processes, and inquires into their character separately, prior to attempting to draw conclusions from them, so that some relations are presented in a new form.

With regard to the part which aqueous vapour plays in the atmosphere, it is usually stated that the heat set free in condensation during the formation of clouds greatly favours the origin of ascending air-currents, but Möler takes another view of the matter. Two columns of air have usually been compared with each other, having at their base similar initial temperature, but in which the decrease of temperature with height proceeds in a different manner, as one column is supposed to contain dry air that is very cold at the upper end, and the other moist air warmed by condensation. But the author considers that this difference of temperature does not actually occur in thi manner, and that all theories based upon this assumption must lead to erroneous results. He states that as the air of the upper strata has risen up previously, it has consequently gone through the process of warming by condensation, so that the increase of heat caused by condensation cannot produce by itself a higher temperature in the ascending current than that possessed by the surrounding air, hence the cause of the upward impulse, which has been attributed to the aqueous vapour of the air, disappears. If it is wished to produce a circulation of the air in two vertical tubes in communication at both ends, the air in the bottom part of the one tube must be warmed, while that in the upper part of the other tube is cooled; but if the source of heat is applied at the top, a condition of stable equilibrium and rest takes place. In the same $n$ ay the condensation of the aqueous vapour causes a warming of the upper strata of air, the effect of which is generally to produce a condition of stable equilibrium, contrary to the theory which assumes that the condensation of the vapour favours the ascending current, and consequently gives rise to depressions. The author attributes the chief cause of the origin of cyclones to horizontal differences of temperature in the earth's almosphere, to the steep gradients of the upper strata caused by them, and the consequent strong movements of the air in those regions. $\mathrm{He}$ agrees in the main with the views of Ferrel, but attributes greater importance to the effect of friction against the rough surface of the earth. The air which rises at the equator, and moves in the upper regions towards the pole, takes, according to the law of the preservation of the moments of rotation, a west to east velocity, whose right-handed deflective force in the northern hemisphere is opposed to the poleward motive effect of the upper gradient.

According to Prof. Moller, this right-handed force over the dry zone, in the belts of high pressure, on both sides of the tropics, and in higher latitudes, becomes so great that a condition of equilibrium of the forces is produced in the direction of the meridians. Apart from local disturbances, the upper wind here follows the parallels of latitude, unless owing to friction, or the mixing of the upper and lower strata, a diminution of the upper current occurs, whereby the meridianal deflecting force of the upper gradients gains the mastery over the decreased right-handed deflective force arising from the centrifugal effect. Only then, and in proportion as this diminution of the upper current occurs, does the upper current follow the meridianal upper gradient. In this case a part of the energy gained in the upper currents of the atmosphere is transferred to the lower strata, so that there the velocities which are directed from west to east increase. The atmosphere, therefore, in the temperate and polar zones is like a caloric machine, which first produces by meridianal gradients of temperature the upper gradients of pressure, and consequently an air current from west 10 east at a great height, whose transference to the lower strata of air depends upon opportunities of friction or mixture of masses of air. The meridianal advance of air in the upper air-current is checked by the centrifugal force; for the advance to the pole increases the velocity of the west wind, and thus the centrifugal right-handed deflective force whose effect stops the meridianal advance of air to the pole. Möller states that this important relation of interchange was not clearly expressed in Ferrel's theory. He first assumes that a circulation between the hot and cold zones takes place unhinderel, and, provided the circulation takes place, he makes the high velocities to exist in the upper current. Ferrel also computes the great forces which would be necessary in order to produce those high velocities, and he admits that these really do not exist. He speaks of this theory as only approximately correct, whereas the computed forces and great meridianal differences of pressure fail in nature, and the high westerly windvelocities, such as his theory requires, do not exist.

Prof. Möller concludes (I) that the regular and undisturbed circulation of the atmosphere between the hot and cold zones is not accomplished in the manner hitherto supposed, and as has been presumed in Ferrel's calculations, and states that if Ferrel's theory is to become of practical use, it will be necessary to study more exactly the relations between the friction of air on the surface of the earth, and especially the friction or the mixture of air between upper and lower strata. (2) If friction of air against the earth's surface is great, the velocity of the winds is less; but if friction, or mixture of air, between upper and lower strata is great, then the lower winds blow more violently. (3) In higher latitudes no storm can be caused by horizontal meridianal gradients of temperature without mixture or friction between the upper and lower strata.

\section{UNIVERSITY AND EDUCATIONAL INTELLIGENCE.}

Oxford.-The Savilian Professor of Astronomy, Mr. H. H. Turner, gave his inaugural address on Friday last, in the new schools, before the Vice-Chancellor and a large audience. The Professor illustrated his subject, "The International Photogra. phic Chart of the Heavens," by numerous lantern-slides, and referred particularly to the large share in the work allotted to the Oxford Observatory, and to the progress which had already been made.

Prof. Sylvanus P. Thompson gave a lecture before the Ashmolean Society on Monday last, on the subject of "Magic Mirrors." The lecture was illustrated by numerous specimens and experiments, and was much appreciated by a large audience.

An election to the Sipthorpian Professorship of Rural Economy is announced to take place in Faster Term, 1894.

NO. I 270, VOL. 49 ] 
Candidates are to send in their applications to the Registrar of the University on or before April 21. The tenure of the Professorship is limited to three years, at the expiration of which the Professor may be re-elected for a further period of three years, but no one may hold the Professorship for more than six years consecutively.

The committee on Degrees for Research have presented a long report to the Hebdomadal Council, which has been approved by that body. The report contains recommendations that will beneficially affect the study of Science in the University. It is proposed that degrees of M.Sc. and M.Litt. shall be established which shall be open $(a)$ to members of the University of Oxford who have taken the B.A. degree, and (b) to students, not being graduates of Oxford, who can give satisfactory proof of general education and fitness to enter upon a special course of study. Three years' residence will be required from the second class of students, or two years from those who have studied for at least two years in a university or local college approved by Convocation, or in an affliated college. No candidate is to be admitted who is under the age of twenty-one, and every candidate not being a member of the University shall be required to matriculate, and to pursue his studies during his term of residence under the supervision of a committee appointed by a special Delegacy to be established for the purpose. In supplicating for the Degree, every candidate must produce a certificate from the Delegacy stating the line of study or research which he has pursued, accompanied by a report, drawn up by the candidate, of the work he has done.

CAMBRIDGE.- Honorary Degrees are to be conferred on the Earl of Kintore, Governor of South Australia, whose adventurous journey across that continent will be remembered, and on Prof. Ramón y Cajal, of Madrid, the Croonian lecturer of this year.

Lord Rayleigh has been appointed an Elector to the Professorships of Chemistry and of Mechanism, Sir R. Ball to the Plumian Professorship, Sir G. Humphry to that of Anatomy, Sir G. G. Stokes to the Jacksonian and the Cavendish Professorships, Dr. D. McAlister to the Downing Chair of Medicine, Dr. Hugo Muiller to the Chair of Mineralogy, Prof. Chiene to the Professorship of Surgery, and Sir James Paget to that of Pathology.

Dr. Shore has been appointed an Examiner in Physiology in place of Dr. A. S. Lea, who is unable to examine owing to illhealth.

ON February 24, the Prince of Wales formally opened the new Polytechnic in Battersea, which has been erected at a cost of nearly $f 60,000$. The institute forms the third of a trio of polytechnics in South London, the others being situated in the Borough-road and at New-cross, respectively. The latter institute, for which the Goldsmiths' Company provided the entire funds, namely $£ 70,000$, and an endowment of $£ 5,000$ a year, has now been open for some time, and has proved a signal success. The Borough-road institute cost about $£ 50,000$, and has been open for about a year.

DR John T. Hewite, Assistant-Demonstrator at the Cambridge University Chemical Laboratory, has been appointed by the Governors of the People's Palace to the vacant Professorship of Chemistry. Dr. Hewitt was a student of the Royal College of Science from 1884 to 1887 . In 1886 he obtained a foundation scholarship at St. John's College, Cambridge, and was awarded a first class in chemistry in both parts of the Natural Science tripos. He afterwards studied in Heidelberg, and took the degree of $\mathrm{Ph} . \mathrm{D}$. in that University in 1892 , having previously obtained a Hutchinson research studentship. Dr, Hewitt is a Doctor of Science of the University of London. where he obtained the exhibition and scholarship for chemistry. $\mathrm{He}$ has also successfully carried out some important chemical researches.

$$
\text { SCIENTIFIC SERIALS. }
$$

The Quarterly Fournal of Microscopical Science for January, 1894, contains observations on the development of the head in Gobius capito, by H. B. Pollard. (Plates 2I and 22.) The stages of development of the brain, mouth, and mesodermal structures are described. The work was carried out during the occupation of the Oxford table at the Naples Zoological Station. -On the head kidney of My'xine glutinosa, by J. W. Kirkaldy. (Plate 23.) It would seem that the pronephros in Myxine may

NO. 1270 , vOL. 49] be regarded as a stage in the phylogenetic reduction of this organ-a reduction which continues in the Pisces until the tubular structure entirely disappears, and, further, that it represents in Myxine the mesoblastic part of the supra-renal bodies. Report on a collection of Amphioxus made by Prof. A. C. Haddon in Torres Straits, 1888-89, by Arthur Willey. All the specimens belonged to the same species, Epigonichthys cultellus, Peters. One of the most remarkable features in its internal organisation is the fact that the gonads occur as a unilateral series of pouches confined to the right side of the body; in connection with this fact the author adds, that often in the Mediterranean form the gonadic pouches of the right side preponderate greatly over those of the left side in number.-On the orientation of the frog's egg, by Dr. T. IH. Morgan and Umé Tsuda. (Plates 24 and 25.) -On the fossil Mammalia from the Stonesfield Slate, by E. S. Goodrich. (Plate 26.) In this excellent account of these very interesting fossils, we have detailed descriptions and figures of Amphitherium Prevostii, Blainv, A. Ozveni, Osborn, Phascolotherium Bucklandi, Broderip, and Amphilestes Broderipii, Owen. The only specimen of Stereognathus ooliticus, Charlesworth, was in too fragmentary a state to be re-described. In a foot-note Prof. E. Ray Lankester gives some graphic reminiscences of another Stonesfield fossil, probably belonging to another species of Stereognathus which was once in his possession.-On a Polynoid with branchiæ (Eupolyodontes Cornishii), by Florence Buchanan. (Plate 27.) This species was found off the mouth of the river Congo by Mr. Cornish, of the cable ship Mirror; a list of the species belonging to the sub-family Acöetidæ is given, and the new species with Polyodontes gulo, Grube, are placed in the new genus Eupolyodontes. - On some Bipinnarix from the English Channel, by Walter Garstang. (Plate 28.) -On Octineon Lindahli (W. B. Carpenter), an undescribed Anthozoon of novel structure, by Dr. G. Herbert Fowler. (Plates 29 and 30.) This remarkable form was dredged in I870 during the Porcupine expedition off the south coast of Spain, not far from Cape St. Vincent, in 364 fathoms of water. It was to have been described by Dr. W. B. Carpenter, who died before doing so ; the specimens were then entrusted to Prof. Moseley, who was unable to finish the work before his death; now we have the memoir completed by Dr. Fowler. In a dead condition the animal presents the form of a thin sandy disc, not exceeding $0^{\prime} 4$ of an inch in diameter. "In Octineon we have an Actinarian with the characteristic habit of a Zoanthid, with the twelve mesenteries of a Hexactinian, and the eight muscles of an Edwardsid," and the evidence seems in favour of the view that it is the type of a new and highly specialised family, descended from true Hexactinian ancestors.

American Meteorological Journal, February.-Recent foreign studies of thunderstorms: IV. Italy, by R. De C. Ward. Systematic study of thunderstorms in Italy was begun in 1877 ; in 1880 the Central Meteorological Office took up the work, and the results have been regularly published in its Annals by Dr. C. Ferrari. The majority of storms come from north-west and west, those from the western quadrant have the greatest velocity, and those which occur in summer have a greater velocity than those in spring or autumn. The chief causes of their development are high temperatures, high vapour pressure, and calm atmosphere. Ferrari's investigation of thunderstorm phenomena is the most complete of any yet published.-Certain climatic features of Maryland, by W. B. Clark. The records of temperature and rainfall, published by the State Weather Service, show an intimate connection between the climate and the topography of the State. The mean annual temperature of the extreme western portion is $50^{\circ}$, while along the eastern border it rises to $58^{\circ}$, and the variations of the seasons are still more pronounced. The rainfall also show's perceptible differences; in the west the average is 38.5 inches, and in other parts nearly 44 inches.-Ten miles above the earth, by H. A. Hazen. This paper contains an account of the ascent of a halloon sent up by M. G. Hermite in Paris, on March 21, 1893 . The highest point reached is computed to be $5 \mathbf{2 , 5 0 0}$ feet, and, according to the law of the diminution in temperature, the lowest temperature was probably not far from $-104^{\circ} \mathrm{F}$., but the trace was lost, owing to the freezing of the ink in the thermograph pen. The other articles are : Measurement of the seasons, by H. Gawthrop (a method is proposed by which, using the daily means as the unit, the progress of a season may be determined and graphically illus trated), and the climate of Louisiana, by R. E. Kerkham, com piled from the State Weather Service records of the past six years. 